\title{
THE USE OF NEW TECHNOLOGIES FOR THE DEVELOPMENT OF PROTECTIVE CLOTHING: COMPARATIVE ANALYSIS OF BODY DIMENSIONS OF STATIC AND DYNAMIC POSTURES AND ITS APPLICATION
}

\author{
Slavica Bogović ${ }^{\text {, Zoran Stjepanovič }}{ }^{2}$, Andrej Cupar², Simona Jevšnik ${ }^{3}$, Beti Rogina-Car1 ${ }^{1}$ Andreja Rudolf²
}

\author{
${ }^{1}$ Faculty of Textile Technology, University of Zagreb, Zagreb, Croatia \\ ${ }^{2}$ Faculty of Mechanical Engineering, University of Maribor, Maribor, Slovenia \\ ${ }^{3}$ Inlas d.o.o., Slovenske Konjice, Slovenia
}

Corresponding author: Zoran Stjepanovič, Faculty of Mechanical Engineering, University of Maribor, Maribor, Slovenia; e-mail: zoran.stjepanovic@um.si

\begin{abstract}
:
In this research, the use of new technologies for the development of special protective overall for sport aircraft pilots was studied, with a focus on a comparative analysis of the static and dynamic body postures' dimensions, intended for the development of the overall's pattern design. For this purpose, digitalization of five male persons was carried out with the 3D human body scanner Vitus Smart by using 3D printed markers, precisely positioned on defined body locations, intended for exact measurement of body dimensions. Male persons, aged between 19 and 35 years with the same athletic body type and different body heights and body mass indexes (BMIs), were scanned in a standard static standing body posture and three dynamic body postures. A comparative analysis between the static and dynamic body postures was carried out. Based on the established body dimensions and girth dimensions of the 3D body model with 3D-modeled compression elements, made-to-measure construction of the overall pattern design was carried out. The function of these compression elements is redistribution of the blood from the lower extremities to the upper body parts at the appearance of high g-forces. Therefore, increased girth dimensions due to the use of compression elements were applied in the overall development process as construction measures with needed ease allowances. The functionality of the developed special protective overall was explored on the scanned 3D body model with 3D-modeled compression elements in a real sitting posture of the sport aircraft pilot in a cab by using virtual prototyping. The virtual simulation technology showed that a well-fitted protective overall for sport aircraft pilots can be developed by using a $3 D$ scanned body model of a person in a sitting posture and its $3 D$ body dimensions.
\end{abstract}

\section{Keywords:}

Anti-g suit, 3D scanning, body measurements, clothing pattern design, clothing virtual simulation

\section{Introduction}

The anti-g suit is a functional protective clothing designed to protect against the gravitational forces to which pilots and astronauts are exposed during flights. Because of the high speeds and the performance of various maneuvers, the body of the pilot is subjected to high acceleration due to gravity and, therefore, the blood is redistributed in the body downward from the upper parts of the body, which may lead to an unexpected loss of consciousness [1-3].

The aim of all anti-g suits is to prevent lowering of the blood from the upper body parts above the heart to the body part below the heart, which is achieved by creating a compression on the blood vessels in the abdomen and lower extremities. Anti-g suits consist of two layers: (1) inextensible material; and (2) tubes positioned in the areas of the body where pressure should be applied. The tubes are interconnected and, depending on the suit type, filled with air or a liquid [1-7]. Today, anti-g suits are designed in such a way that the fitting of the overall to the body can be adjusted by means of a zipper, tie bands, or ropes. Similarly, compression tubes are also attached $[1,6,7]$.
The anti-g suit is a protective clothing item whose shape and construction components are the basic elements of protection, while in the most protective clothing items, the protection is achieved with textile material $[5,8,9]$. Thus, an anti-g suit should be adjusted to the body dimensions of the wearer or should be tailored in a made-to-measure manner.

The clothing must fit the body shape and simultaneously provide the wearer freedom or sufficient space for body movement during the carrying out of desired activities in standing, sitting, or other body postures. To provide the wearer with ergonomic comfort of a clothing made from a fabric, in the first place, the clothing pattern designs and appropriate ease allowances must be considered. Classifications of the ease allowances are many: static, dynamic, styling, fabric ease allowances, and so on [10-12]. Nevertheless, the wearing ease allowance, also the so-called dynamic ease allowance, can obstruct body movements and impede the functional use of clothing. The results of a study on protective overalls and the evaluation of garment design and fit showed that adding a specific amount of the crotch ease to the back pattern piece of the protective overall is more appropriate than adding a specific amount of the crotch ease to the front and back pattern pieces 
as prescribed by the traditional method [13]. This study clearly shows that defining the appropriate wearing ease allowance is fundamentally important in clothing product development, especially for protective clothing in the form of an overall intended for standing and mostly sitting posture activities, as in the case of the aircraft pilot [4, 9]. In these preliminary studies, the dynamic standing and sitting body postures were examined for the development of a special protective overall for a sport aircraft pilot by using virtual prototyping. The dynamic body postures and related human body dimensions were also explored for the purpose of defining a protocol for automatic computer-based determination of measurements on a 3D body model [14].

In recent years, virtual prototyping in the ready- and custommade clothing development process by using the 3D body scanning and computer-aided design (CAD) technologies has increased. The breakthrough is definitely geared toward supporting the development of new products, such as clothing for physically impaired persons, persons with physical deformities, the elderly, or persons who, in carrying out various activities, use specific body postures [15-19]. Virtual prototyping is also used for the virtual reconstruction of historical clothing, development of the female torso classification and method of patterns shaping, and the human-friendly design of a virtual system "female body dress" [20-22]. Recently, research on automatic data extraction from the scanned raw data file as input data for the CAD clothing designing system was carried out with the purpose of production of individualized work apparel, intended for special task units and army clothing [23]. In this research, a strong correlation between the 3D scanned anthropometric measurements and automatically gained pattern designs of clothing was obtained at each testing stage. In addition, an upgraded use of the 3D body scanning can be seen in the paper [24], wherein 3D scanning was used to evaluate the impact of design solutions on the thermal insulation of clothing and clothing systems.

In another study [4], the proportional body dimensions of five male persons having different body types, body mass indexes (BMIs), and body heights were compared with the calculated proportional body dimensions by using a construction system for men's clothing (M. Müller \& Sohn) [25]. Obvious differences between the measured and calculated proportional body dimensions for the hip depth, especially for the back length, were found, while during the change in body dimension with regard to the change in the body postures, no special trend was observed from the point of view of the different body types.

The aim of this research was to study the body dimensions in a standard static standing body posture and in three dynamic body postures for five male persons having the same body type and different body heights and BMls, as well as to explore the functionality of a developed made-to-measure special protective overall for sport aircraft pilots based on the established body dimensions by using 3D scanning, 3D modeling, 3D printing, and virtual prototyping technologies.

\section{Experimental}

In this study, 3D body scanning of five male persons aged between 19 and 35 years, having the same athletic (A) body type, calculated according to the standard International Organization for Standardization/Technical Reports (ISO/TR) 10652 [26] and different body heights and BMls (Table 1), was carried out in different body postures (Figure 1). Comparison between the body dimensions in the standard static standing body posture and three dynamic body postures was performed on the digitized cloud points of bodies by using a ScanWorks program. Furthermore, the compression elements intended for installation inside the overall (tubes) were 3D modeled on the sitting 3D body model with the aim to determine the body girths with needed ease allowances. In addition, the overall pattern design was developed based on the established body dimensions and girth dimensions of the 3D body model with 3D-modeled compression elements for virtual prototyping and inspection of the overall fit to the body by using the OptiTex CAD program.

\subsection{Process of 3D body scanning and determination of body dimensions}

The 3D human body scanner Vitus Smart was used for 3D body scanning in a restricted scanning area of $1 \mathrm{~m} \times 1 \mathrm{~m}$ (University of Zagreb, Faculty of Textile Technology, Croatia). We examined the static standard standing posture and three dynamic body postures, namely, standing posture with arms forward, standing posture in a forward bend, and sitting posture with arms forward to knees (body posture in a pilot cab) (Figure 1). The scanning postures were selected according to the specific movements that can affect construction of the special

Table 1. Tested persons' specifications

\begin{tabular}{|c|c|c|c|c|c|}
\hline Body type* & $\begin{array}{l}\text { Mean drop } \\
\text { value* }^{*}\end{array}$ & $\begin{array}{l}\text { Scanned } \\
\text { person }\end{array}$ & $\begin{array}{l}\text { Body height of the } \\
\text { tested person }(\mathrm{cm})\end{array}$ & $\begin{array}{c}\text { Calculated mean drop value of the } \\
\text { tested person }(\mathrm{cm})\end{array}$ & BMI \\
\hline Athletic (A) & 16 & $A$ & 178.5 & 23.8 & 25.1 \\
\hline Regular (R) & 12 & B & 179.4 & 14.8 & 28.0 \\
\hline Portly (P) & 6 & C & 189.1 & 17.2 & 28.5 \\
\hline Stout (S) & 0 & $D$ & 190.5 & 16.2 & 30.3 \\
\hline Corpulent (C) & -6 & $E$ & 193.1 & 16.5 & 20.1 \\
\hline
\end{tabular}

*Note: Descriptive names for the five body types and their mean drop values based on the standard ISO/TR 10652 [26]. 
protective overall pattern design for a sport aircraft pilot. Given that the main purpose of using an overall for piloting is to meet the comfort and functional wearing requirements during piloting (Body Posture 4), the other two dynamic postures were chosen as the extreme standing postures for tasks requiring a maximum movement of arms to the forward position (Body Posture 2) and tasks requiring a maximum forward bend of the trunk (Body Posture 3). Before the process of digitalization, the markers were placed on the human body at precisely defined anthropometrical points and the other key points on the body between which body dimensions were precisely measured in different body postures. Markers were placed on the neck, shoulder, chest, waist, hip, and knee locations. Markers were $3 \mathrm{D}$ printed in the form of a pyramid for extraction of the exact virtual body dimensions (Figure 1).

In this research, 24 body dimensions were measured in all defined body postures according to the standard ISO 8559 [27] (Figure 2; Table 2). In addition, five body dimensions that standard ISO 8559 does not specify were also measured, namely, the front and back overall lengths (up, low) and knee length. The lengths of the overall upper part were measured from the shoulder line to the hip line on the front and back parts $\left(\mathrm{FOL}^{\text {up }}, \mathrm{BOL}^{\mathrm{up}}\right)$. The lengths of the overall lower part were measured on the front from the hip line over the knees to the floor and on the back from the hip line along the central part of the leg to the floor $\left(\mathrm{FOL}_{\text {low }}, \mathrm{BOL}_{\text {low }}\right)$. The longitudinal region of the knee, in this study - the so-called knee length $(\mathrm{KL})$ - was measured between the markers positioned $8 \mathrm{~cm}$ above and $8 \mathrm{~cm}$ below the knee line, as can be seen in Figure 1.

All body dimensions were measured by using the ScanWorks program. The 3D scanned point clouds of bodies enabled the extraction of cross sections of the cloud points defined on the specific body locations and, therefore, the exact comparison of the body dimensions during the changes of body postures. The cross sections of the cloud points, the measured body dimensions with abbreviations of body dimensions, and the labeling of body dimensions with respect to the scanned person and body posture are presented in Figure 2 .
The measured body dimensions with their descriptions for all body postures are collated in Table 2. Some of the body dimensions were not virtually measured: chest depth in Postures 2 and 3, thigh girth and total crotch length in Posture 4 , and knee length in Postures 2 and 3. The knee length in Postures 2 and 3 (dynamic standing postures) was assumed to be of the same length as in the standard standing Posture 1; therefore, it has not been measured in Postures 2 and 3 . In addition, it has not been possible to accurately determine the shoulder point in the neck (Posture 2) on the 3D body as well as at the shoulder and the waist points (Posture 3). In Posture 4 , it was not possible to accurately measure the circumference of the thigh and the total crotch length due to the necessary modeling of the $3 \mathrm{D}$ body mesh in the crotch area (a location that is difficult to reach when scanning in a sitting posture).

\subsection{Investigation of the developed special protective overall's functionality in a virtual environment}

The pattern design of a special protective overall for a sport aircraft pilot was developed for a male person A. Construction of the anti-g overall pattern design was based on (a) the body dimensions in different body postures, especially in a sitting posture (Table 2) and (b) the girth dimensions of a sitting 3D body model with 3D-modeled compression elements (Figure 3), which were used as the construction measures. Compression techniques for sport aircraft pilots are known and described in various sources [1, 7]. Therefore, the compression elements that serve for filling the overall with a liquid or air were modeled at known locations on the body. The use of such a 3D body model allowed us to determine the necessary body girths with ease allowances for construction of a well-fitted overall pattern design. Virtual testing of the anti-g overall's functionality was carried out by using the OptiTex CAD program. For the virtual display of the anti-g suit's functionality, the real sitting body posture in a pilot cab was used.

\section{Results and discussion}

The analysis of the body dimensions was carried out for the (a)

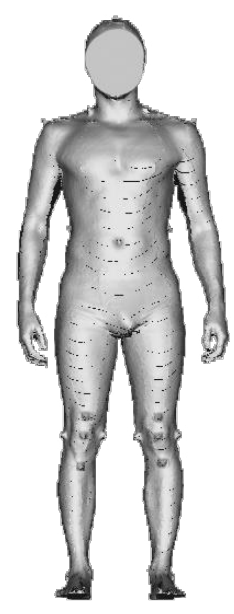

1

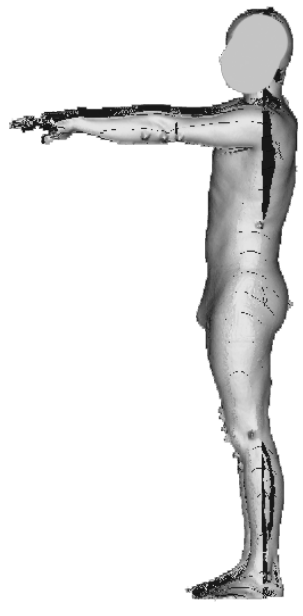

2

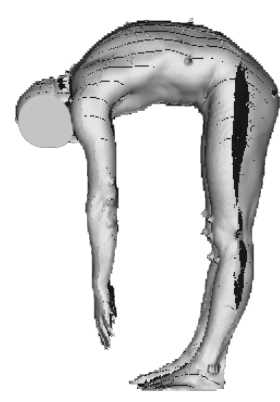

3

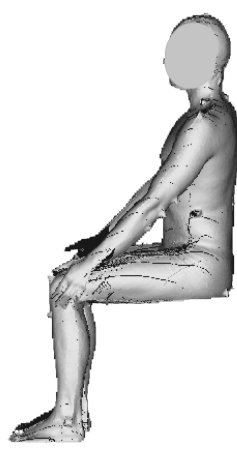

4

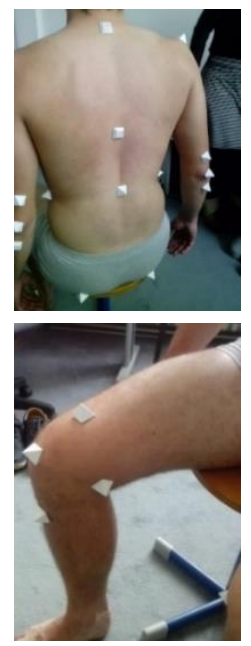

Figure 1. Scanning postures (1-4) and setting up of markers on the body before 3D scanning 


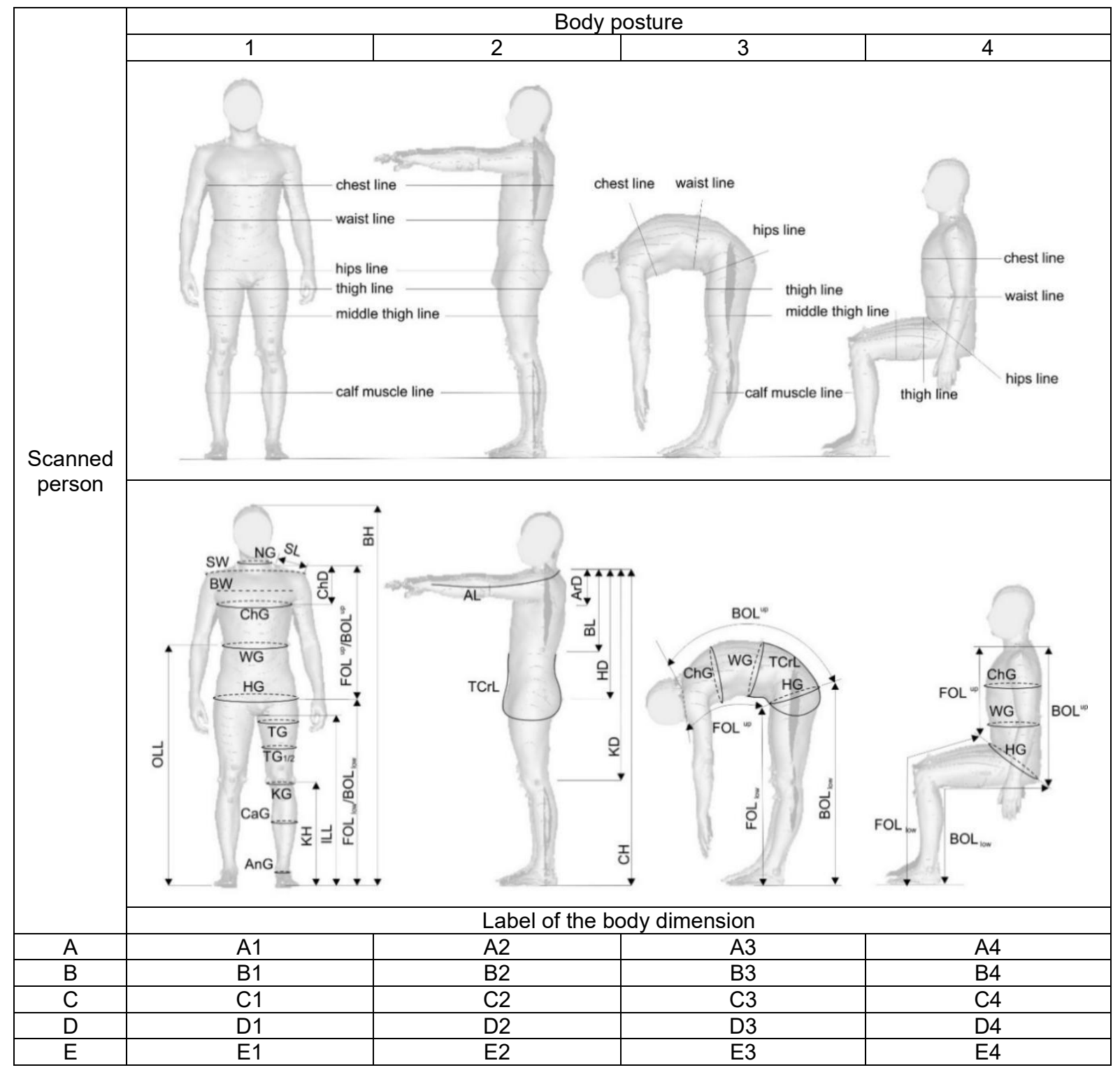

Figure 2. Defined cross sections, body dimensions, and labeling of body dimensions with respect to the scanned person and body posture

most specific dimensions for construction of the overall lengths and (b) most specific dimensions for construction of the overall widths, which were measured in the same way and located at different positions in the different body postures.

The measured total front overall length $\left(\mathrm{FOL}^{\text {up }}+\mathrm{FOL}_{\text {low }}=\mathrm{FOL}\right)$ and total back overall length $\left(\mathrm{BOL}^{\mathrm{up}}+\mathrm{BOL}_{\text {low }}=\mathrm{BOL}\right)$, and in particular, the overall dimensions of the upper parts (FOL ${ }^{\text {up }}$, $\left.\mathrm{BOL}{ }^{\text {up }}\right)$ and lower parts $\left(\mathrm{FOL}_{\text {low }}, \mathrm{BOL}_{\text {low }}\right)$, are shown in Figure 4.

Differences in the bodies' dimensions between dynamic postures and standard standing posture (D) were calculated. In Table 3, the most relevant differences of the bodies' dimensions are presented for the sitting Posture 4 for all scanned persons. They are considered most important for construction of the overall pattern design that fits the body at all necessary locations. A positive value means an increase in the body dimension when changing the posture from a standard standing to a sitting posture, while a negative value means a decrease of the body dimension in a sitting posture.
With respect to the different body postures, changes of the overall lengths were expected, especially in the standing posture in the forward bend and in the sitting posture with the arms forward to the knees. The total front overall length (FOL) was decreased in the forward bend for all scanned persons (Body Posture 3) (Figure 4a), in particular, due to a greater decrease in the front overall upper length (FOL ${ }^{\text {up }}$ ) compared to the front overall lower length $\left(\mathrm{FOL}_{\text {low }}\right)$ (Figures $4 \mathrm{c}$ and $4 \mathrm{~d}$ ). The back overall length (BOL) was increased in the forward bend (Figure 4a), in particular, due to a greater increase in the back overall upper length ( $\mathrm{BOL}{ }^{\text {up }}$ ) compared to the back overall lower length $\left(\mathrm{BOL}_{\text {low }}\right)$ (Figures $4 \mathrm{e}$ and $\left.4 \mathrm{f}\right)$. This also confirms an increase in the cervical height $(\mathrm{CH})$, back length $(\mathrm{BL})$, and especially the hip depth (HD) for all scanned persons (Figure $5 a)$. At the same time, the outside leg length (OLL) increased due to the rotation of the body at the hips when bent forward (Figure 5b).

In the sitting posture with the arms forward to the knees, the FOL was decreased for all scanned persons (Body Posture 4) (Figure $4 a$ ), in particular, due to a greater decrease in the front 


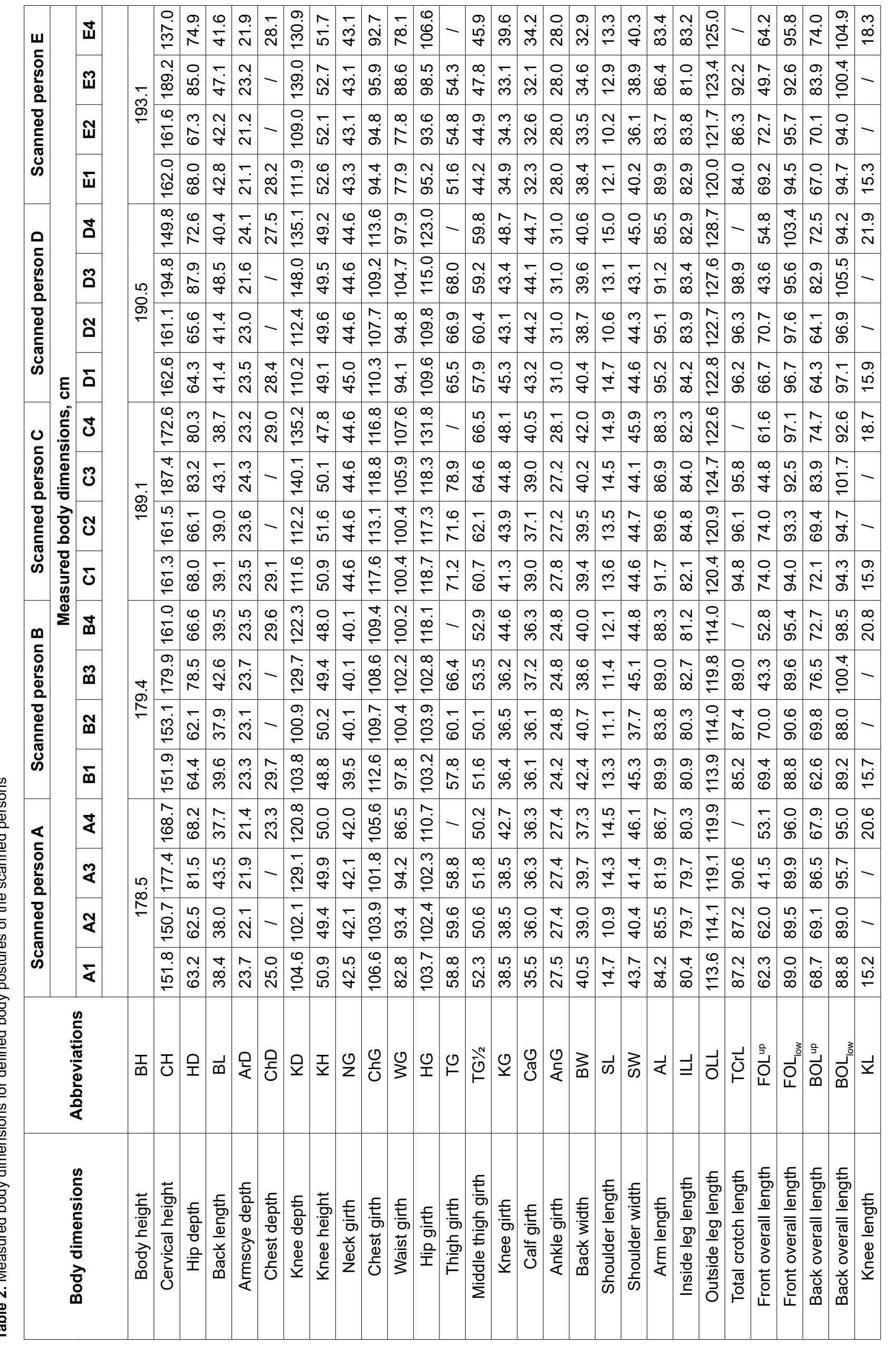




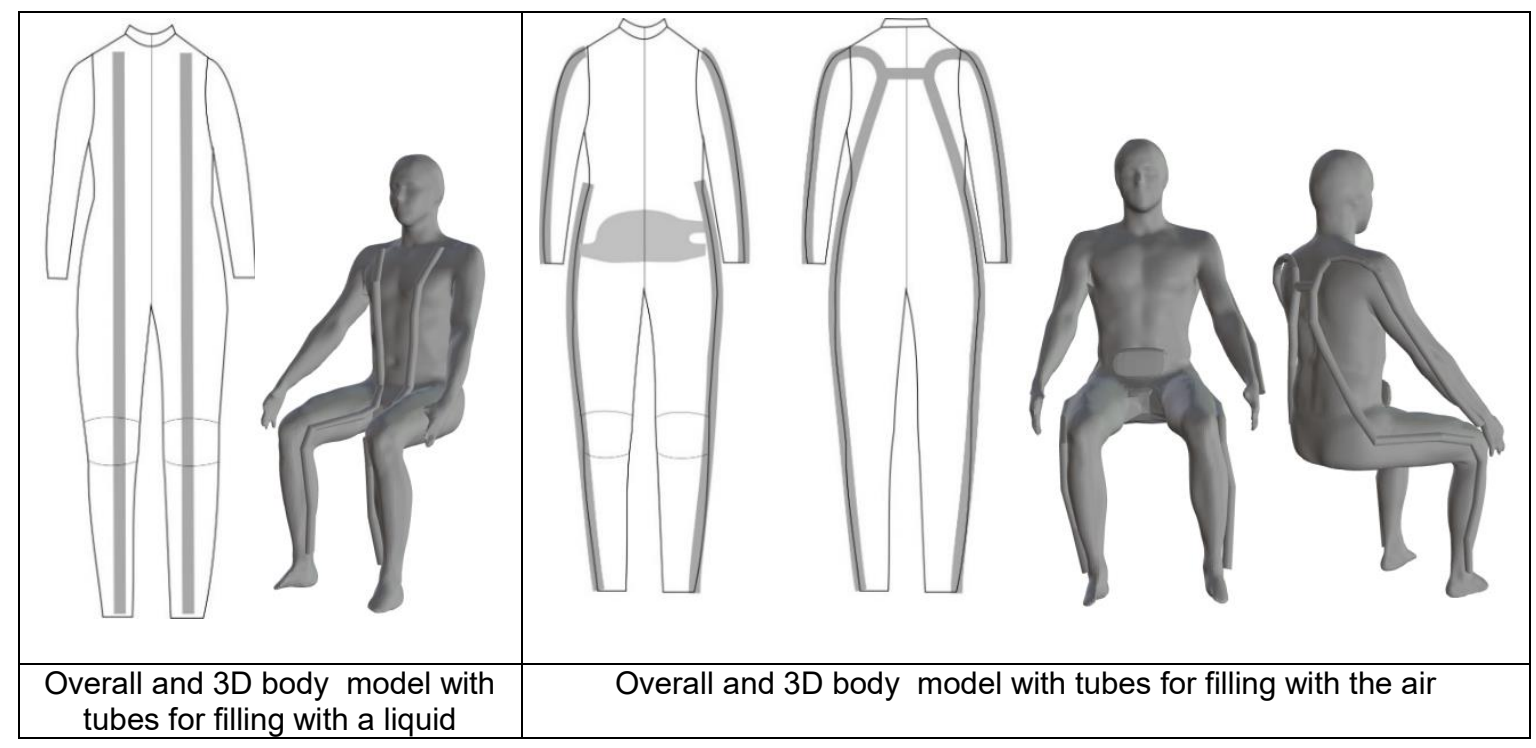

Figure 3. Drawings of overalls and 3D body models with tubes for filling with a liquid and air

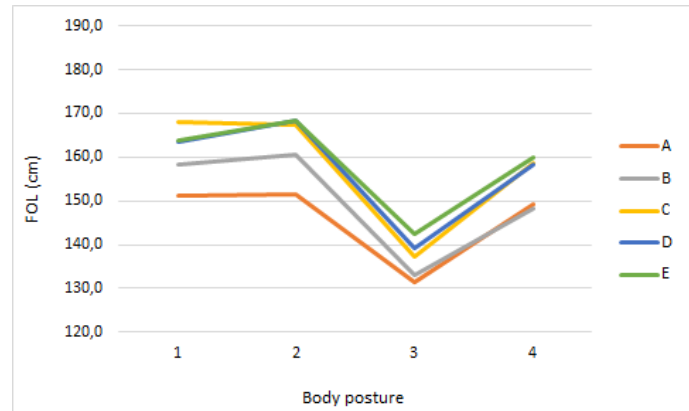

a.

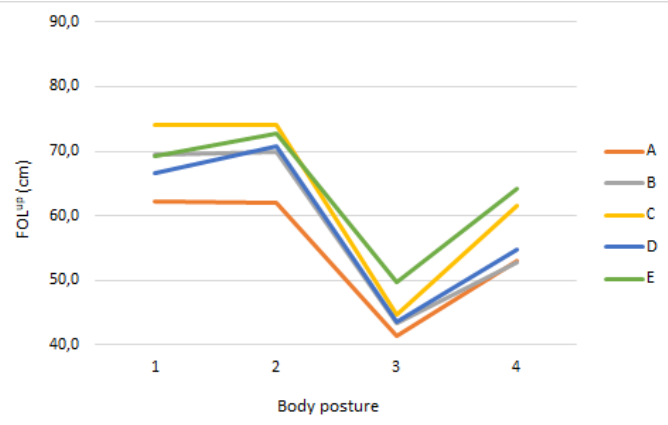

C.

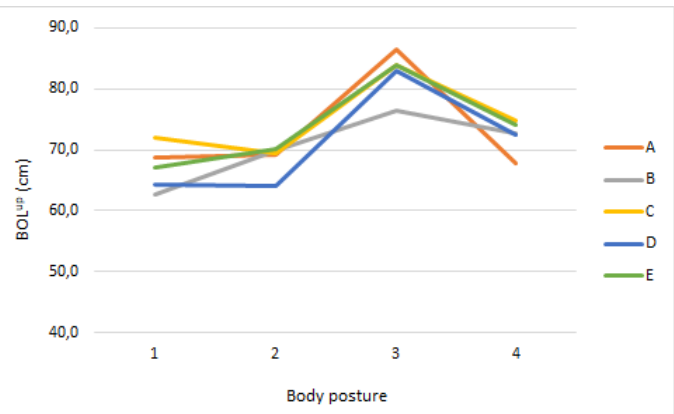

e.

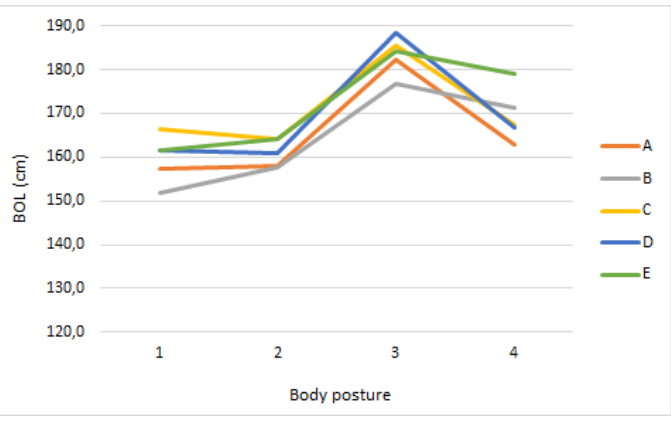

b.

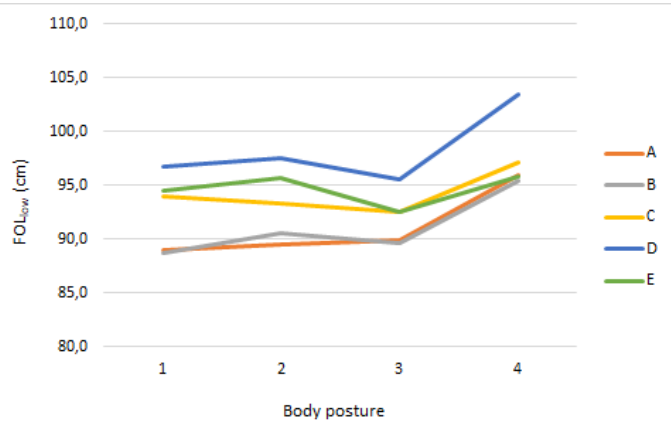

d.

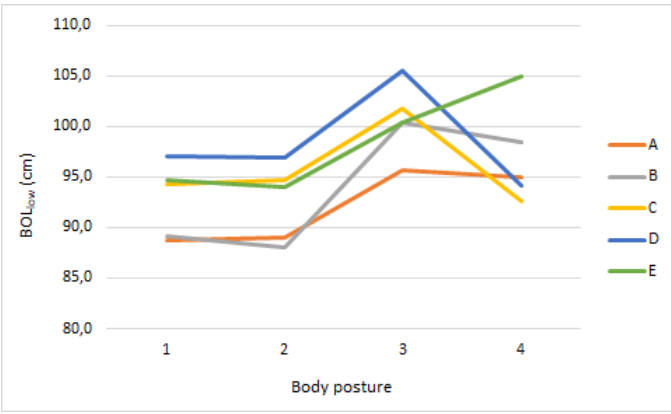

f.

Figure 4. Comparison of the overall lengths for different body postures 

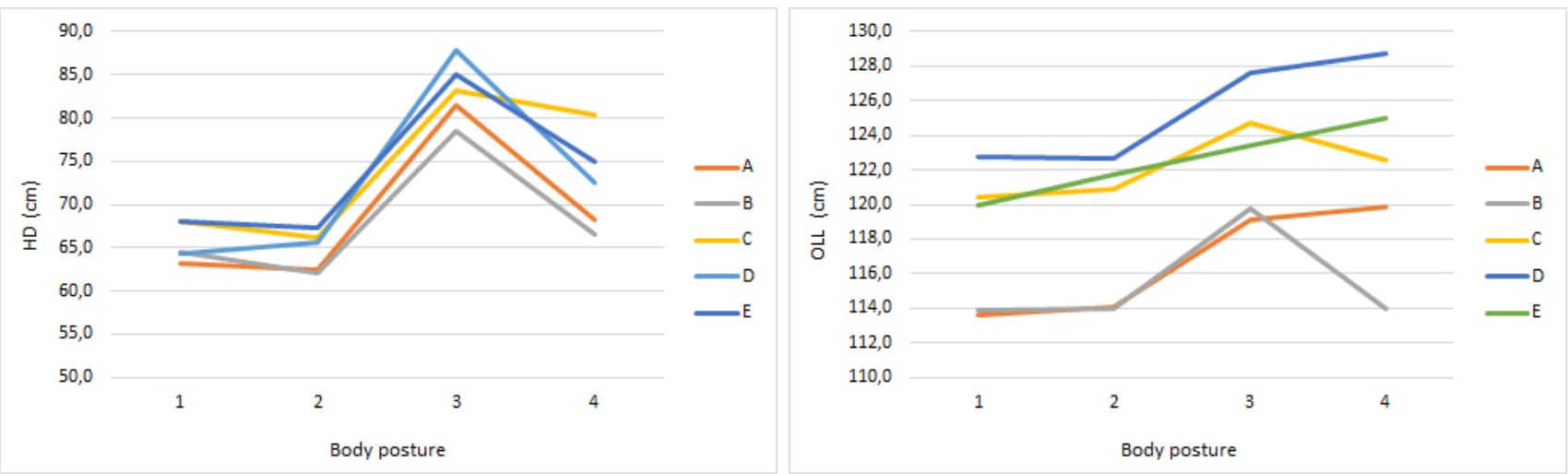

Figure 5. Comparison of the hip depth and outside leg length for different body postures

overall upper length, while for the front overall lower length, an increase in this dimension appeared (Figures 4c and 4d). The biggest difference in change of the dimension $\mathrm{FOL}^{\text {up }}$ was $16.6 \mathrm{~cm}$ for the person B4 and the smallest was $5.0 \mathrm{~cm}$ for the person E4 (the highest person), while the biggest difference in change of the dimension $\mathrm{FOL}_{\text {low }}$ was $7.0 \mathrm{~cm}$ for the person $\mathrm{A} 4$ (the lowest person) and the smallest as $1.3 \mathrm{~cm}$ for the person E4 (the highest person) (Table 3).

The BOL was increased in the sitting posture (Figure 4b) due to an increase in the back overall upper length and the back overall lower length (Figures $4 \mathrm{e}$ and $4 \mathrm{f}$ ). This also confirms an increase in the cervical heights and hip depth, while the back lengths (BLs) in the sitting posture and standing posture were similar for all scanned persons (Table 2). A deviation from this trend could be detected for the scanned person A4 for the dimension $\mathrm{BOL}^{\text {up }}$ and for the scanned persons $\mathrm{C}$ and $\mathrm{D}$ for the dimension $\mathrm{BOL}_{\text {low }}$.

The biggest difference in change of the dimension $\mathrm{BOL}^{\text {up }}$ was $10.4 \mathrm{~cm}$ for the person B4 and the smallest was $0.8 \mathrm{~cm}$ for the person $A 4$, while the biggest difference in change of the dimension $\mathrm{BOL}_{\text {low }}$ was $10.2 \mathrm{~cm}$ for the person $\mathrm{E} 4$ (the highest person) and the smallest was $1.3 \mathrm{~cm}$ for the person C4 (Table 3). When sitting, the outside leg length (OLL) was also increased due to the rotation of the body at the hips (Figure $5 b$ ), while the bend of the knee in the sitting posture did not affect the change of the body dimension OLL. The difference in change of the dimension OLL did not increase with the body height of the scanned persons A4-E4 (Table 3).

As expected, an increase in the front overall lower length is a consequence of the increase in the knee length for all scanned persons and varies between $2.8 \mathrm{~cm}$ (C3) and $6.0 \mathrm{~cm}$ (D4) (Figure 6, Table 3). No connections between increasing body heights/BMls and an increase in the knee length were found in the sitting posture.

Regarding the comparison of the body dimensions in static and dynamic body postures, all scanned persons had the athletic body type defined by standard ISO/TR 10652 [24] and different body heights (Table 1). It was expected that changes in the length dimensions would appear with an increase in the body height. Table 3 clearly shows that this is not the case. Therefore,

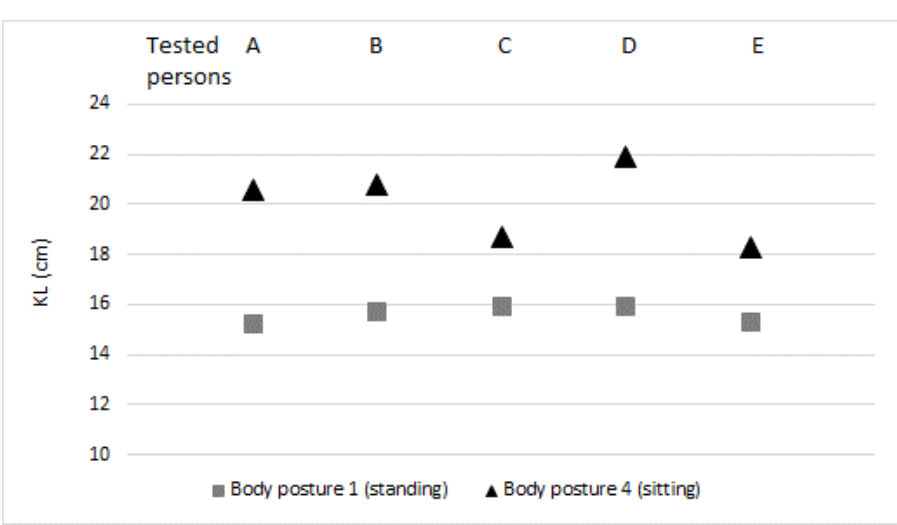

Figure 6. Comparison of the knee length for standing and sitting body postures

the changes in the length dimensions could be attributed to different distributions of the body parts (trunk, extremities) of the scanned subjects. This can be concluded primarily from the dimensions of the hip depth and the knee height, which did not increase with the body height of the scanned persons (Table 2).

When observing the main girths of the body (chest, waist, and hip girths), a significant increase of the hip girth when changing the body posture from a standing to a sitting posture can be seen (Table 2, Figure 7). A higher increase in the hip girth was expected in a sitting posture compared to the waist girth in a sitting posture (Table 3 ). An interesting increase in the waist girth can be observed when changing the body posture from a standard standing to the standing in a forward bend and sitting postures for all tested persons (Table 2). This can be attributed to the more relaxed upper body part (trunk) in a forward bend and sitting posture compared to the situation in the standing posture. The chest girth is also altered by the changing of the body posture, i.e., a decrease for all dynamic body postures was detected almost for all tested persons. This can be attributed to the preservation of non-motion during the scanning in a standing posture with arms removed from the body and breathing during the scanning process.

In addition, a significant increase in girth for the thigh, middle thigh, knee, and calf was detected with the change of the body posture from a standard standing to all other dynamic body 


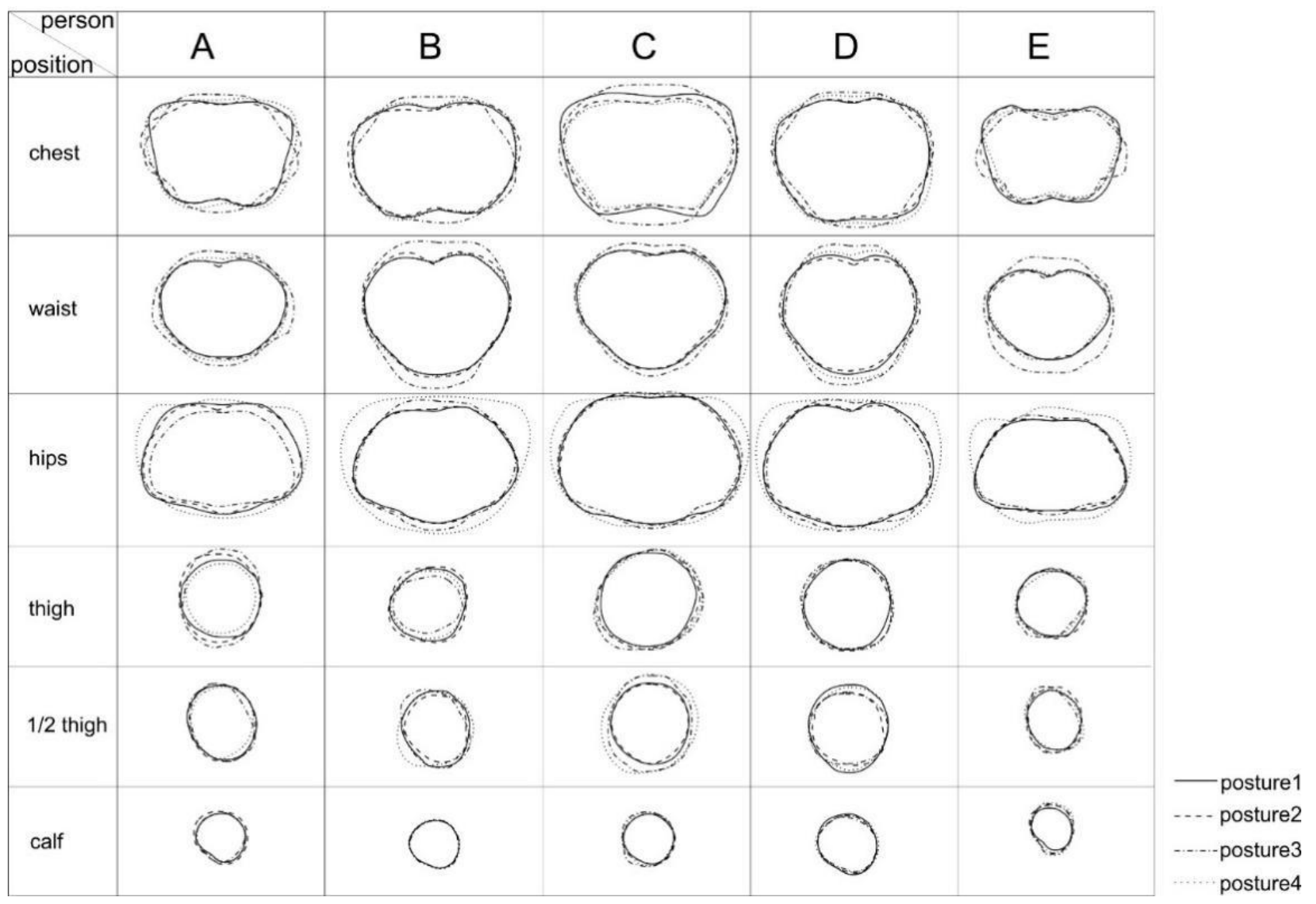

Figure 7. Cross sections of the cloud points for all scanned persons and body postures

Table 3. Some differences in the bodies' dimensions for the sitting body Posture 4

\begin{tabular}{|c|c|c|c|c|c|}
\hline \multirow{2}{*}{ Body dimensions } & \multicolumn{5}{|c|}{ Differences in bodies' dimensions in a sitting posture, cm } \\
\cline { 2 - 6 } & A4 & B4 & C4 & D4 & E4 \\
\hline DFOL $^{\text {up }}$ & -9.2 & -16.6 & -12.4 & -11.9 & -5.0 \\
\hline DFOL $_{\text {low }}$ & 7.0 & 6.6 & 3.1 & 6.7 & 1.3 \\
\hline DBOL $^{\text {up }}$ & -0.8 & 10.1 & 2.6 & 8.2 & 7.0 \\
\hline DBOL $_{\text {low }}$ & 6.2 & 9.3 & -1.7 & -2.9 & 10.2 \\
\hline DOLL $^{\text {DKL }}$ & 6.3 & 0.1 & 2.2 & 5.9 & 5.0 \\
\hline DChG & 5.4 & 5.1 & 2.8 & 6.0 & 3.0 \\
\hline DWG & -1.0 & -3.2 & -0.8 & 3.3 & -1.7 \\
\hline DHG & 3.7 & 2.4 & 7.2 & 3.8 & 0.2 \\
\hline DTG $1 / 2$ & 7.0 & 14.9 & 13.1 & 13.4 & 11.4 \\
\hline DKG & -2.1 & 1.3 & 5.8 & 1.9 & 1.7 \\
\hline DCG & 4.2 & 8.2 & 6.2 & 3.4 & 4.7 \\
\hline & 0.8 & 0.2 & 0.5 & 1.5 & 1.9 \\
\hline
\end{tabular}


postures (Table 2, Figure 7). In the sitting posture, the knee girth changed the most and the calf girth the least (Table 3), which was also expected.

When observing Table 3, we cannot see any connection between increasing body heights of the scanned persons ( $A-$ E) and changes in the body girths. This could be attributed to the different constitutions of the scanned persons indicated by BMls (Table 1). This can be concluded primarily from the girth dimensions for the chest, waist, hips, thigh, and knee, as well as for the knee height, which did not increase with the body height of the scanned subjects (Tables 2 and 3 ).

Based on the analysis of the body dimensions of the scanned persons with the same body type and different body heights and BMls, no relationship between the changes in the body dimensions and body height during the change in the body posture was found. The greatest changes in body dimensions, especially in the length dimensions, occur when changing the posture from the standard standing to the standing with the forward band of the trunk (Posture 3 ) and to the sitting Posture 4. When comparing the body dimensions in Postures 3 and 4 , we realized that a major change occurred mainly in the $\mathrm{BOL}$ up dimension in Posture 3, while the differences between the other overall length dimensions were smaller for all scanned persons. The priority focus of the overall development before performing Posture 3 is on using the overall for piloting and providing comfort and the necessary overall functionality during piloting in a sitting Posture 4. These findings related to the investigated test persons indicate that for construction of the overall pattern design, it is necessary to take into account the body dimensions in dynamic postures, especially in a sitting posture for both the sitting $3 \mathrm{D}$ body model without and with 3D-modeled compression elements on the 3D body model in order to assure an exact fit of the overall to the body. This is especially important for a one-piece garment or overall, presented in this study as a special garment, which should protect the sport aircraft pilot against possible loss of consciousness because of high g-forces.

In this study, we wanted to develop a made-to-measure pattern design of the protective overall and to show its advantages when compared to the overalls that can be found on the market (Figure 8). Such overalls must be customized to the body of individuals by means of tightening with zippers, ropes, or strips, which is first of all a lengthy process. On the other hand, a rigidly tied overall can disturb the pilot's activities and comfort when sitting. For these reasons, we focused on the development of an overall well fitted to the body, which requires precise body dimensions and necessary minimum ease allowances.

Construction of the protective overall pattern design was carried out for a scanned person A and his body dimensions in a sitting posture (Table 2). At the same time, we paid attention to the tubes intended for filling with liquid or air, which create the necessary compression on the body and contribute to the greater dimensions of the overall. Therefore, we also took into account the ease allowances on specific locations when constructing the overall pattern design based on girth dimensions of the 3D body model with compression elements. The leg girths are of the utmost importance for construction of the overall pattern design because of the needed compression on the lower extremities of the body. In addition to all the usually required body dimensions, the dimensions of the front and back overall lengths (upper and lower dimensions) were used in the development of the overall pattern design. Different lengths of the overall's lower part (overall front and back lower lengths) were adjusted with the outside leg length (side seam) in the location from the hip line to the floor with a specially shaped pattern piece at the knee area (Figure 9).

The virtual representation of the overall prototype for the sport aircraft pilot is shown in Figure 9. It can be seen that the developed overall nicely fits to the body at the key parts of the body, i.e., at the legs and the trunk, while the sleeves are looser. The overall opens in the middle at the front with a zipper, which is necessary for dressing. The compression elements can be seen through the 3D overall's meshed model in the form of tubes on the front part intended for filling with a liquid (Figure 9a) and tubes on the front part with a compression element on the abdomen for filling with air (Figure 9b). Some differences in the overalls' tensions can be seen on the shoulders, abdomen, and calf parts due to the different compression techniques. Compression on the thigh and calf is also visible. Due to the dressing requirements, the ankle part of the trousers is very wide. Therefore, in order to ensure the compression on the lower part of legs, this overall should be tightened with a zipper in the side seams from the ankle to the calf.

The virtual simulation showed that a well-fitted protective
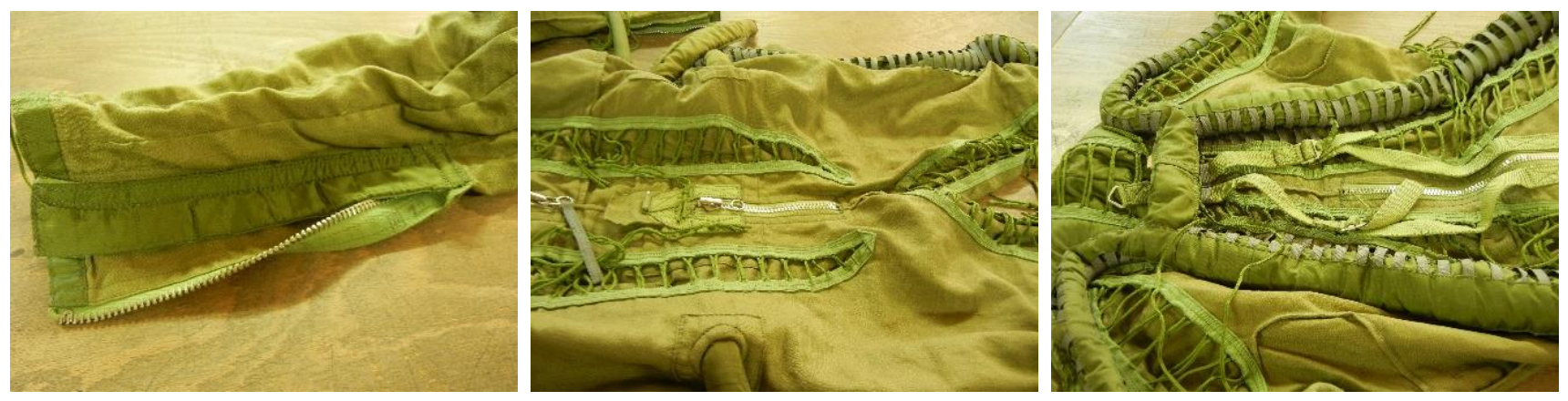

Figure 8. Zipper and ropes for adjustments of the overall to the body [6] 


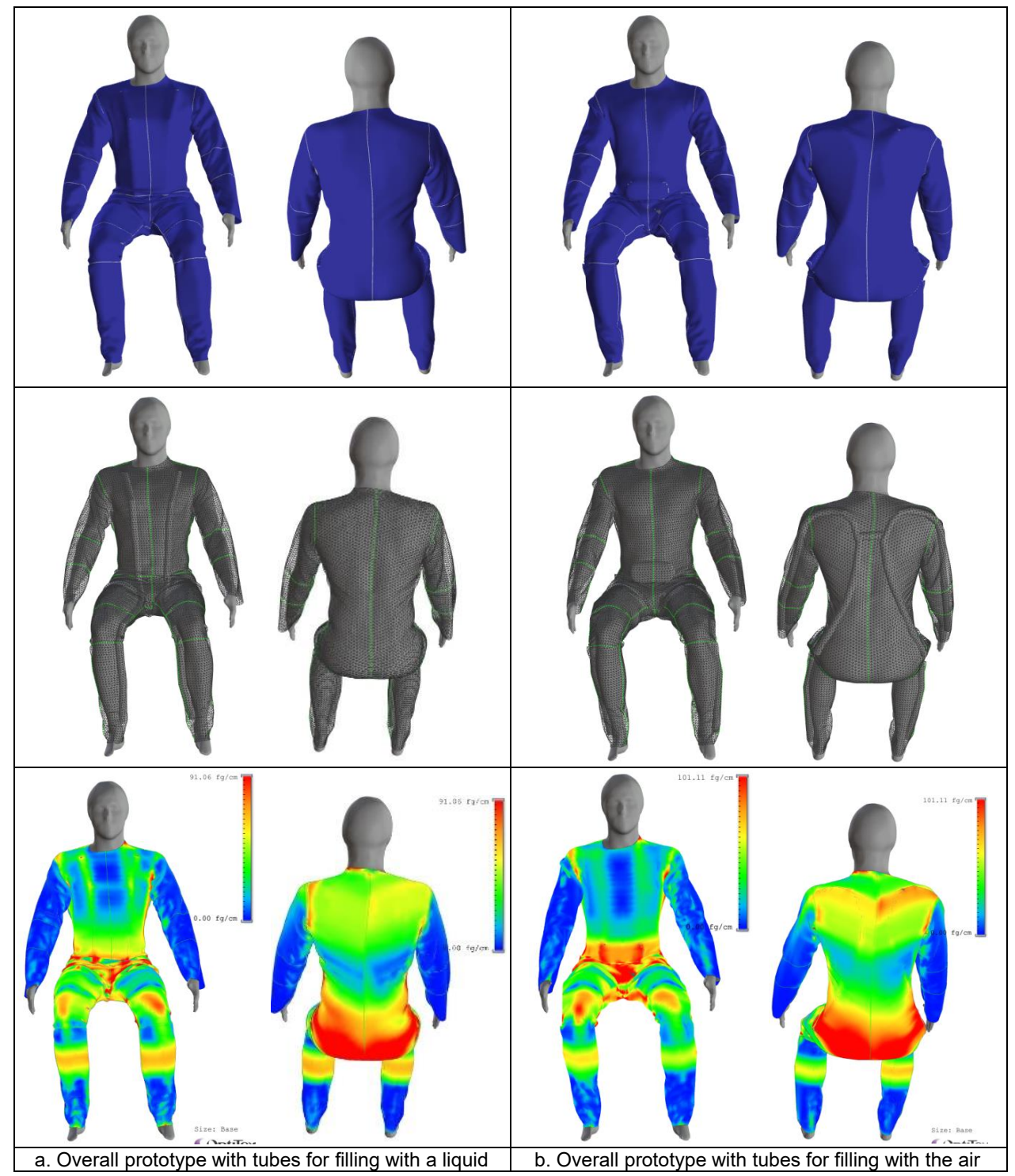

Figure 9. Virtual simulations of the overall prototype on the scanned 3D body model with tubes for filling with a liquid or air

overall for sport aircraft pilots can be developed by using a $3 \mathrm{D}$ scanned body model of a person in a sitting posture and the exactly measured $3 D$ body dimensions by help of the $3 D$ printed markers located at the key points on the body.

\section{Conclusions}

In this study, a comparison of the body dimensions in a static standard standing body posture and three dynamic body postures was carried out, aimed to develop an ergonomically fitted overall for the sport aircraft pilot, by using 3D scanning, modeling, and virtual simulation technologies. All scanned persons had the athletic body types and different body heights and BMls. Almost all body dimensions among the 29 researched ones were changed with a change of the body posture from a static standard standing to the dynamic standing and sitting postures. It was expected that with a change in the body posture, the length dimensions as well as the changes in these dimensions would be increased with increased body heights of the scanned persons. It was found that this was not the case. Therefore, the arising changes could be attributed to the different distributions of the body parts (trunk, extremities) of the scanned subjects. This was primarily confirmed by the dimensions of the hip depth and the knee height, which did not increase with the body height of the scanned persons. This fact and the research carried out suggest that a well-fitting special protective garment needs to be made according to the exact body dimensions of the individual, which can be achieved by using new technologies or their interactive effect during the development process of a special protective clothing. From this point of view, the results of this study are promising and can be stated as a solid basis for further research work focused on development of such and similar special garments.

\section{Acknowledgments}

The authors express their thanks to the bilateral cooperation between the Republic of Slovenia and the Republic of Croatia (BI-HR/16-17-050) and the Slovenian Research Agency (Research Program P2-0123: Clothing Science, Comfort and 
Textile Materials), as well as to the EC Program Erasmus+, project TexMatrix, the funding from which enabled the completion of this study.

\section{References}

[1] Jenkins, D. R. (2012). Dressing for altitude: U.S. aviation pressure suits - Wiley Post to space shuttle. October 26, 2012. Web site: https://www.nasa.gov/connect/ebooks/ dress_for_altitude_detail.html.

[2] Rood, G. (2014). A brief history of flying clothing. Journal of Aeronautical History, 1, 3-54. Web site: https://www. aerosociety.com/media/4847/a-brief-history-of-flyingclothing.pdf.

[3] Zhang, W., Xu, Y., Zhang, H., Zou, L., Peng, H., et al. (2016). Study on the operation of liquid-filled anti-G suit based on finite element method. In: Goonetilleke, R., Karwowski, W. (Eds.). Advances in physical ergonomics and human factors. Proceedings of the AHFE 2016. International Conference on Physical Ergonomics and Human Factors. Springer (Cham).

[4] Rudolf, A., Bogović, S., Rogina Car, B., Stjepanovič, Z., Jevšnik, S., et al. (2017). Virtual prototyping of special protective clothing for sport aircraft pilots. In: Frydrych, I., Bartkowiak, G., Pawlowa, M. (Eds.). Innovations in protective and E-textiles in balance with comfort and Ecology. Lodz University of Technology (Lodz). pp. 84-96.

[5] Ding, L., Xianxue Li X., Hedge, A., Hu, H., Feathers, D., et al. (2015). Optimizing the physical ergonomics indices for the use of partial pressure suits. Applied Ergonomics, 47, 72-83.

[6] Štorga, V., Bogović, S. (2016). Protective anti-G suit. In: Kirin, S. Book of Proceedings 6th International Professional and Scientific Conference. Occupational Safety and Health. Karlovac University of Applied Sciences (Karlovac).

[7] Stuwe, R. New Concepts in pilot G-protection, Presentation at the Royal Aeronautical Society- Hamburg Branch, January 28, 2010. Web site: http://www.fzt.haw-hamburg. de/pers/Scholz/dg/r/hh/text_2010_01_28_Pilot_Gprotection.pdf

[8] Bogović, S. (2012). Construction of functional protective clothing. In: Bischof Vukušić, S. (Ed.). Functional Protective Textiles. University of Zagreb, Faculty of Textile Technology (Zagreb).

[9] Rudolf, A., Bogović, S., Rogina Car, B., Cupar, A., Stjepanovič, Z., et al. (2017). Textile forms' in computer simulation techniques. In: Cvetković, D. (Ed.). Computer Simulation. InTech (Rijeka). pp. 67-94.

[10] Shan, Y., Huang, G., Qian, X. (2012). Research overview on apparel fit. Computing in information communication technology. AISC 161. Spring-Verlag (Berlin Heidelberg). pp. 39-44.

[11] Gill, S. (2011). Improving garment fit and function through ease quantification. Journal of Fashion Marketing and Management, 15(2), 228-241.

[12] Ng, R., Cheung, L. F., Yu, W. (2008). Dynamic ease allowance in arm raising of functional garments. Sen'i Gakkaishi, 64(9), 236-243.
[13] Huck, J., Maganga, O., Kim, Y. (1997). Protective overalls: evaluation of garment design and fit. International Journal of Clothing Science and Technology, 9(1), 45-61.

[14] Petrak, S., Mahnić Naglić, M. (2017). Dynamic anthropometry - defining protocols for automatic body measurement. Tekstilec, 60(4), 254-262.

[15] Rudolf, A., Cupar, A., Kozar, T., Stjepanovič, Z. (2015). Study regarding the virtual prototyping of garments for paraplegics. Fibers and Polymers. 16(5), 1177-1192.

[16] Kozar, T., Rudolf, A., Cupar, A., Jevšnik, S., Stjepanovič, Z. (2014). Designing an adaptive $3 D$ body model suitable for people with limited body abilities. Journal of Textile Science \& Engineering, 4(5), 1-13.

[17] Rudolf, A., Brajlih, T., Drstvenšek, I., Šauperl, O. (2016). New medical technologies and their impact on functional ability: $3 D$ scanning and simulation of functional garment. In: Lovrenov, Ž. (Ed.). Research, Education, and Practice in Insurance Medicine and Social Security: Book of Abstracts 21st EUMAS Congress. Domus (Ljubljana), pp. 176.

[18] Rudolf, A. Repnik, J. Drstvenšek, I., Görlichová. L., Salobir, A., et al. (2017). New technologies in the development of ergonomic garments for wheelchair users in a virtual environment. Industria Textila, 68(2), 83-94.

[19] Hong, Y., Bruniaux, P., Zeng, X., Liu, K., Curteza, A., et al. (2018). Visual-simulation-based personalized garment block design method for physically disabled people with scoliosis (PDPS). Autex Research Journal. 18(1), 35-45.

[20] Kuzmichev, V., Moskvin, A., Moskvina, M. (2018). Virtual reconstruction of historical men's suit. Autex Research Journal. 18(3), 281-294.

[21] Wu, X., Kuzmichev, V., Peng, T. (2018). Development of female torso classification and method of patterns shaping. Autex Research Journal. Published online July 19, 2018, doi: 10.1515/aut-2018-0011.

[22] Guo, M., Kuzmichev, V. E., Adolphe, D. C. (2015). Humanfriendly design of virtual system "female body-dress". Autex Research Journal, 15(1), 19-29.

[23] Dāboliṇa, I., Viḷumsone, A., Dāboliṇš, J., Strazdiene, E., Lapkovska, E. (2018). Usability of $3 D$ anthropometrical data in CAD/CAM patterns. International Journal of Fashion Design, Technology and Education, 11(1), 41-52.

[24] Špelić, I., Rogale, D., Mihelić Bogdanić, A., Petrak, S., Mahnić Naglić, M. (2018). Changes in ensembles' thermal insulation according to garment's fit and length based on athletic figure. Fibers and Polymers, 19(6), 1278-1287.

[25] Deutsche Bekleidungs-Akademie München. (1999). HAKA-Schnittkonstruktionen nach M. Müller \& Sohn: ausgewählte Konstruktionsbeiträge der Rundschau für internationale Herrenmodemode. Rundschau-Verlag (München).

[26] ISO/TR 10652:1991 (E). Standard sizing systems for clothes.

[27] ISO 8559-1:2017. Size designation of clothes - Part 1: Anthropometric definitions for body measurement. 